\title{
Wearable robotic exoskeleton for overground gait training in sub-acute and chronic hemiparetic stroke patients: preliminary results
}

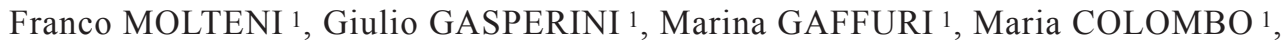 \\ Chiara GIOVANZANA ${ }^{1}$, Chiara LORENZON ${ }^{1}$, Nico FARINA ${ }^{1}$, Giovanni CANNAVIELLO ${ }^{2}$, \\ Stefano SCARANO ${ }^{3}$, Davide PROSERPIO ${ }^{1}$, Davide LIBERALI ${ }^{1}$, Eleonora GUANZIROLI ${ }^{1}$ *
}

${ }^{1}$ Villa Beretta Rehabilitation Center, Valduce Hospital, Costa Masnaga, Lecco, Italy; ${ }^{2}$ Department of Medical and Surgical Specialties and Dentistry, Second University of Naples, Naples, Italy; ${ }^{3}$ Department of Biomedical Sciences for Health, University of Milan, Milan, Italy

*Corresponding author: Eleonora Guanziroli, Villa Beretta Rehabilitation Center, Valduce Hospital, Via N. Sauro 17, 23845 Costa Masnaga (LC), Italy, E-mail: eleonora.guanziroli@gmail.com

\section{A B S T R A C T}

BACKGROUND: Recovery of therapeutic or functional ambulatory capacity in post-stroke patients is a primary goal of rehabilitation. Wearable powered exoskeletons allow patients with gait dysfunctions to perform over-ground gait training, even immediately after the acute event. AIM: To investigate the feasibility and the clinical effects of an over-ground walking training with a wearable powered exoskeleton in sub-acute and chronic stroke patients.

DESIGN: Prospective, pilot pre-post, open label, non-randomized experimental study.

SETTING: A single neurological rehabilitation center for inpatients and outpatients.

POPULATION: Twenty-three post-stroke patients were enrolled: 12 sub-acute (mean age: $43.8 \pm 13.3$ years, 5 male and 7 female, 7 right hemiparesis and 5 left hemiparesis) and 11 chronic (mean age: $55.5 \pm 15.9$ years, 7 male and 4 female, 4 right hemiparesis and 7 left hemiparesis) patients.

METHODS: Patients underwent 12 sessions ( $60 \mathrm{~min} / \mathrm{session}, 3$ times/week) of walking rehabilitation training using Ekso ${ }^{\mathrm{TM}}$, a wearable bionic suit that enables individuals with lower extremity disabilities and minimal forearm strength to stand up, sit down and walk over a flat hard surface with a full weight-bearing reciprocal gait. Clinical evaluations were performed at the beginning of the training period (t0), after 6 sessions ( $\mathrm{t} 1)$ and after 12 sessions (t2) and were based on the Ashworth scale, Motricity Index, Trunk Control Test, Functional Ambulation Scale, 10-Meter Walking Test, 6-Minute Walking Test, and Walking Handicap Scale. Wilcoxon's test $(\mathrm{P}<0.05)$ was used to detect significant changes.

RESULTS: Statistically significant improvements were observed at the three assessment periods for both groups in Motricity Index, Functional Ambulation Scale, 10-meter walking test, and 6-minute walking test. Sub-acute patients achieved statistically significant improvement in Trunk Control Test and Walking Handicap Scale at t0-t2. Sub-acute and chronic patient did not achieve significant improvement in Ashworth scale at $\mathrm{t} 0-\mathrm{t} 2$.

CONCLUSIONS: Twelve sessions of over-ground gait training using a powered wearable robotic exoskeleton improved ambulatory functions in sub-acute and chronic post-stroke patients. Large, randomized multicenter studies are needed to confirm these preliminary data. CLINICAL REHABILITATION IMPACT: To plan a completely new individual tailored robotic rehabilitation strategy after stroke, including task-oriented over-ground gait training.

(Cite this article as: Molteni F, Gasperini G, Gaffuri M, Colombo M, Giovanzana C, Lorenzon C, et al. Wearable robotic exoskeleton for overground gait training in sub-acute and chronic hemiparetic stroke patients: preliminary results. Eur J Phys Rehabil Med 2017;53:676-84. DOI: 10.23736/ S1973-9087.17.04591-9)

Key words: Stroke - Rehabilitation - Exoskeleton device - Neurologic gait disorders.

Stroke is a leading cause of acquired disability in adults worldwide. ${ }^{1}$ Hemiparesis, with loss of coordination in upper and lower limb joints, is one of the most disabling consequences. Post stroke locomotor impairments are often associated with abnormal timing and intensity in recruitment of lower limb muscles, 


\section{COPYRIGHT ${ }^{\odot} 2017$ EDIZIONI MINERVA MEDICA}

thereby affecting muscle coordination and walking ability. ${ }^{2-5}$ Literature reports indicate that $30-40 \%$ of stroke survivors have limited or no walking ability even after rehabilitation; 6,7 for this reason there is an ongoing need to advance the efficacy of gait rehabilitation for stroke survivors. ${ }^{8}$

Recent evidence demonstrates that the central nervous system (CNS) can reorganize after injury and that reorganization in a functional meaningful way depends on motor activity during rehabilitative training. ${ }^{9,10}$ There is growing evidence that a high number of task-oriented, repetitive movements based on the principles of motor learning can improve muscular strength, movement coordination and functions in neurological patients. ${ }^{11,12}$ Task-specific training exoskeletons with body weight supported treadmill training have been developed for gait rehabilitation after stroke. These technologies can provide higher number of repetitions for walking practice than conventional gait training, avoiding additional strain on therapists. However, there is conflicting evidence regarding the efficacy of treadmill-based robotics for gait training compared to conventional therapy. ${ }^{8}$

In a literature review of electromechanical devices for gait rehabilitation in stroke patients, ${ }^{13}$ authors concluded that patients who receive treadmill robotic-assisted gait training in combination with physiotherapy after stroke are more likely to achieve independent walking than patients who receive gait training without these devices. Other systematic reviews report no difference in gait speed and endurance when comparing conventional therapy and electromechanical treadmillbased robotics involving equal intensity and duration of training. ${ }^{14}$ However, restricting patients to training on a treadmill does not allow the patient to practice realworld gait scenarios, such as walking over non-smooth surfaces, stepping over objects, and practicing standing up and sitting down. Moreover, during treadmill robotic training with body weight support, patients could have less control ${ }^{15}$ over the initiation of each single step and a lack of variability in visual spatial flow. ${ }^{16}$ These features represent an essential challenge for reaching functional overground walking.

Wearable powered exoskeletons are a recent technological development allowing individuals with lower limbs pathologies and/or weakness to walk on a hard, flat surface. ${ }^{17}$ The devices incorporate actuators that move the patient's legs through the gait cycle in the sag- ittal plane. The robotic device guides the legs through pre-programmed physiological gait patterns while the subject experiences near-normal proprioceptive input during limb loading. The pre-programmed walking pattern is quite similar to a normal gait and it includes gait cycle timing, interlimb and interjoint coordination, appropriate limb loading and afferent signals. ${ }^{18}$

Wearable powered exoskeletons are in accord with modern principles of overground gait rehabilitation. In particular, these device should maximize loading of the lower limbs instead of the upper extremities during training, promote hip extension and limb unloading synchronization with simultaneous loading of the contralateral lower limb to promote swing initiation, and promote step initiation from a stride position to allow weight transfer from an extended and loaded limb forward to the unloaded limb. ${ }^{19-22}$ The powered exoskeleton's kinematic chain maps the human limb anatomy and the control emulates human neuromotor control; thus, it is a promising new tool for gait rehabilitation and challenges the way in which neurological rehabilitation training should be provided.

Initially, wearable powered exoskeletons were designed as assistive devices that allowed complete spinal cord injury (SCI) patients' safe ambulation. ${ }^{23,24}$

There is a paucity of published data on powered robotic exoskeletons for gait rehabilitation in post-stroke patients. The aim of this study was to investigate the feasibility and the clinical effects of overground walking training with a wearable powered exoskeleton (Ekso ${ }^{\mathrm{TM}}$, Ekso Bionics, Richmond, CA, USA) in sub-acute and chronic stroke patients.

\section{Materials and methods}

A total of 23 stroke patients were referred to and enrolled for study at Villa Beretta Rehabilitation Center (Costa Masnaga, Lecco, Italy) from December 2013 to December 2014. Time from the acute event ranged from 25 days to 2350 days and included sub-acute $(<180$ days from acute event) and chronic ( $>180$ days from acute event) patients. Characteristics of the 12 sub-acute and 11 chronic patients are presented in Table I.

Patients were screened by a board-certified physiatrist, who was experienced in the biomechanics of gait and the use of robotic device technology and who screened potential study participants for eligibility. 


\section{COPYRIGHT $^{(} 2017$ EDIZIONI MINERVA MEDICA}

TABLE I.-Characteristics of sub-acute and chronic patients.

\begin{tabular}{lcc}
\hline Characteristics & $\begin{array}{c}\text { Sub-acute patients } \\
(\mathrm{N} .=12)\end{array}$ & $\begin{array}{c}\text { Chronic patients } \\
(\mathrm{N} .=11)\end{array}$ \\
\hline Mean age, years & $43.8 \pm 13.3$ & $55.5 \pm 15.9$ \\
Gender, N. & 5 & \\
$\quad$ Male & 7 & 4 \\
$\quad$ Female & & 4 \\
Hemiparesis, N. & 5 & 7 \\
$\quad$ Left & 7 & 4 \\
$\quad$ Right & & \\
$\begin{array}{l}\text { Etiology } \\
\quad \text { Ischemia }\end{array} \quad 7$ & 6 \\
$\quad$ Hemorrhagia & 4 & 5 \\
$\begin{array}{l}\text { Mean time from acute event, days } \\
\text { (range) }\end{array}$ & 66.4 & 597.5 \\
\hline
\end{tabular}

The inclusion criteria were: hemiparesis secondary to a single onset unilateral stroke, no significant lower extremity joint pain, no major sensory deficits, no significant lower limb contractures, and stable cardiovascular and respiratory conditions. The exclusion criteria were: any orthopedic or neurologic conditions in addition to stroke, any significant musculoskeletal problem that could limit hip and knee extension or ankle plantar flexion, and incapacity to understand instructions and give written formal consent.

Written informed consent was obtained from each subject. Ethical approval of the treatment and of the evaluation protocol was granted by the joint local Ethics Committee for the provinces of Lecco, Como and Sondrio (protocol no. 0040564/15U, issued on 30/09/2015).

\section{Intervention: a robotic device for overground gait training}

Ekso is a wearable bionic suit: it enables individuals with lower limb disabilities and minimal forearm strength to stand, sit and walk over a flat hard surface with a full weight-bearing reciprocal gait under the supervision of a physical therapist. Ekso is intended for non-ambulatory and ambulatory post-stroke patients, spinal cord complete and incomplete injury patients with different etiology, and traumatic brain injury patients. It can also be used as a therapeutic device in patients who must re-learn walking with a proper step pattern and functional weight shift by moving the patient's legs through a customizable predefined patient-tailored kinematic pattern.
Ekso weighs $23 \mathrm{~kg}$ and can be used by individuals who weigh up to $100 \mathrm{~kg}$ and range from 160 to $190 \mathrm{~cm}$ of height. Patients must have a standing hip width at maximum of $43 \mathrm{~cm}$. Ekso is equipped with 4 batterypowered motors at the hips and knees, which are designed to support or replace deficient neuromuscular function.

\section{Ekso setting definitions: trigger and assistance}

There are four types of actuation for each patient step: FirstStep ${ }^{\mathrm{TM}}$, by which a physical therapist actuates steps with a button push; ActiveStep ${ }^{\mathrm{TM}}$, by which the patient takes control of actuating steps via buttons on the crutches or walker; ProStep ${ }^{\mathrm{TM}}$, by which the patient achieves the next step by moving body weight laterally and then forward; ProStep Plus ${ }^{\mathrm{TM}}$, by which steps are triggered by the user's lateral weight shift. The amount of power contribution to one or both legs during walking can be tuned with three types of assistance for each single step. The first is Bilateral Max Assist, in which Ekso provides full power to both legs. No strength is required from the patient: only proper balance and weight shifts are required to achieve walking. The second is Adaptive Assist, in which patients with any amount of lower extremity strength contribute to their walking efforts; Ekso dynamically adjusts to produce a smooth, consistent gait. The third is Fixed Assist, whereby Ekso legs provide a fixed amount of prespecified power to help patients to complete steps in a specified amount of time.

\section{Study design}

This was a prospective, pilot pre-post, open label, non-randomized experimental study. Enrolled patients underwent 12 sessions $(60 \mathrm{~min} / \mathrm{session}$ for 3 times a week) of walking rehabilitation training using the powered wearable robotic device. ProStep Plus ${ }^{\mathrm{TM}}$ and Bilateral Max Assist were used as the default settings in this study. Before the start of the training period, the gait cycle kinematic parameters of the exoskeleton were finetuned using surface electromyography (sEMG). The sEMG of tibialis anterior, soleus, rectus femoris, and hamstring muscles was collected bilaterally. Different exoskeleton parameters were set for each patient and sEMG was collected. The choice of the best configuration was defined on the basis of the best muscles activa- 


\section{COPYRIGHT $^{(} 2017$ EDIZIONI MINERVA MEDICA}

TABLE II.-Clinical Scale for activities ICF domain in sub-acute patients.

\begin{tabular}{lccc}
\hline \multirow{2}{*}{ ICF domain } & \multicolumn{3}{c}{ Period } \\
\cline { 2 - 4 } & $\mathrm{t}_{0}$ & $\mathrm{t}_{1}$ & $\mathrm{t}_{2}$ \\
\hline Ashworth Scale & & & \\
$\quad$ Hip abductors & $0(0-1)$ & $0(0-1)$ & $0(0-1)$ \\
Knee extensors & $0(0-3)$ & $0(0-1)$ & $0(0-1)$ \\
$\quad$ Ankle plantar flexors & $0(0-3)$ & $1.5(0-3)$ & $1(0-3)$ \\
Motricity Index & & & \\
$\quad$ Total & $33.5(1-65)$ & $43.5(10-65)$ & $59(19-$ \\
& & & $100)$ \\
Hip & $14(0-25)$ & $19(9-25)$ & $19(9-33)$ \\
Knee & $16.5(0-25)$ & $19(0-25)$ & $22(9-33)$ \\
Ankle & $4.5(0-14)$ & $9(0-19)$ & $14(0-33)$ \\
\hline
\end{tabular}

Data are presented as median (range).

ICF: International Classification of Functioning, Disability and Health; $\mathrm{t}_{0}$ : beginning of training period; $t_{1}$ : after 6 sessions; $t_{2}$ : after 12 sessions.

tion timing according to clinical practice; in this way, a customized and tailored robotic treatment was defined.

Sub-acute patients underwent robotic training in conjunction with conventional physiotherapy training, whereas chronic patients underwent only overground robotic gait training. A clinical evaluation based on the International Classification of Functioning, Disability and Health (ICF), ${ }^{25}$ was undertaken at three points in the overall training period: at the beginning of the training period $\left(\mathrm{t}_{0}\right)$, after 6 sessions $\left(\mathrm{t}_{1}\right)$ and after 12 sessions of the training period $\left(\mathrm{t}_{2}\right)$.

For the body function and structure ICF domain, we adopted the Ashworth (Ash) scale to evaluate hip adductor, knee extensor, and ankle plantar flexor muscles spasticity 26 and the Motricity Index (MI) to measure strength in the lower extremities. ${ }^{27}$ For the activities ICF domain, the Trunk Control Test (TCT) was used to evaluate trunk control, not only during the maintenance of the sitting position, but also during "dynamic conditions." 28 The Functional Ambulation Scale (FAC) was used to evaluate basic motor skills necessary for functional ambulation. ${ }^{29}$ For the activities ICF domain, we also used the 10-Meter Walking Test $(10 \mathrm{mWT})$ to evaluate walking speed over a short distance 30 and the 6-Minute Walking Test (6minWT) as a sub-maximal test of aerobic capacity/endurance to assess distance walked during 6 minutes. ${ }^{31}$ For the participation ICF domain, the Walking Handicap Scale (WHS) was used to assess quantitatively a person's customary level of walking ability at home and in the community. ${ }^{32}$
TABLE III.-Clinical scale for activities and participation ICF domains for sub-acute patients.

\begin{tabular}{lccc}
\hline \multirow{2}{*}{\multicolumn{1}{c}{ ICF domain }} & \multicolumn{3}{c}{ Period } \\
\cline { 2 - 4 } & $\mathrm{t}_{0}$ & $\mathrm{t}_{1}$ & $\mathrm{t}_{2}$ \\
\hline Trunk Control Test & $61(12-74)$ & $61(24-74)$ & $61(24-100)$ \\
Functional Ambulation Scale & $0.5(0-3)$ & $2.5(0-4)$ & $3(0-4)$ \\
10mWT, s & $27.8 \pm 12.8$ & $29.4 \pm 21.1$ & $29.2 \pm 25.4$ \\
10mWT, steps & $18.4 \pm 12.4$ & $16.5 \pm 8.4$ & $15.7 \pm 7.5$ \\
10mWT, m/s & $0.46 \pm 0.29$ & $0.49 \pm 0.28$ & $0.56 \pm 0.33$ \\
6minWT, m & $157.6 \pm 77.6$ & $192.1 \pm 103.7$ & $205.1 \pm 113.2$ \\
Walking Handicap Scale & $1(1-3)$ & $1.5(1-4)$ & $2(1-4)$ \\
\hline
\end{tabular}

Data are presented as median (range) or as mean $\pm \mathrm{SD}$.

ICF: International Classification of Functioning, Disability and Health; 10mWT: 10-Meter Walk Test; 6minWT: 6-Minute Walk Test.

\section{Statistical analysis}

The Friedman test, useful to make non-parametric multiple comparisons, and then a post-hoc analysis with Wilcoxon and Bonferroni correction of $\mathrm{P}$ values was performed. Wilcoxon test, a non-parametric test that compares two paired groups, was employed to detect significant changes between data at baseline $\left(\mathrm{t}_{0}\right)$, after 6 sessions $\left(t_{1}\right)$, and at the end of 12 sessions of the training period $\left(t_{2}\right)$. Statistical analyses were performed with SPSS Statistics (IBM Corporation, Armonk, NY, USA); statistical significance was set at 0.05 .

\section{Results}

\section{Sub-acute patients}

Twelve sub-acute patients were evaluated at $t_{0}, t_{1}$, and $t_{2}$. In Table II, the median and range of values of Ashworth and motricity index scales for sub-acute patients are reported. The Ashworth scale, measured at hip adductor muscles $\left(\mathrm{P}_{\mathrm{t} 0-\mathrm{t} 1}=0.99, \mathrm{P}_{\mathrm{t} 0-\mathrm{t} 2}=0.99\right)$, at knee extensor muscles $\left(\mathrm{P}_{\mathrm{t} 0-\mathrm{t} 1}=0.63, \mathrm{P}_{\mathrm{t} 0-\mathrm{t} 2}=0.99\right)$, and at ankle plantar flexor muscles $\left(\mathrm{P}_{\mathrm{t} 0-\mathrm{t} 1}=0.25, \mathrm{P}_{\mathrm{t} 0-\mathrm{t} 2}=0.50\right)$, did not reveal statistical differences. The total score of Motricity Index showed significant improvements at $\mathrm{t}_{0}-\mathrm{t}_{1}$ $(\mathrm{P}=0.002), \mathrm{t}_{1}-\mathrm{t}_{2}(\mathrm{P}=0.0078)$, and $\mathrm{t}_{0}-\mathrm{t}_{2}(\mathrm{P}=0.001)$. The partial scores of the MI revealed significant improvements at hip level at $\mathrm{t}_{0}-\mathrm{t}_{1}(\mathrm{P}=0.0078)$ and $\mathrm{t}_{0}-\mathrm{t}_{2}(\mathrm{P}=0.002)$. MI evaluated at knee level evidenced significant change at $\mathrm{t}_{0}-\mathrm{t}_{1}(\mathrm{P}=0.0313)$ and $\mathrm{t}_{0}-\mathrm{t}_{2}(\mathrm{P}=0.0078)$. MI evaluated at ankle level also revealed significant improvement at $\mathrm{t}_{0}-\mathrm{t}_{2}(\mathrm{P}=0.0156)$. 


\section{COPYRIGHT $^{(} 2017$ EDIZIONI MINERVA MEDICA}

TABLE IV.-Clinical scale for body function and structure ICF domain for chronic patients.

\begin{tabular}{lccc}
\hline \multirow{2}{*}{ ICF domain } & \multicolumn{3}{c}{ Period } \\
\cline { 2 - 4 } & $\mathrm{t}_{0}$ & $\mathrm{t}_{1}$ & $\mathrm{t}_{2}$ \\
\hline Ashworth Scale & & & \\
$\quad$ Hip abductors & $0(0-3)$ & $0(0-3)$ & $0(0-3)$ \\
$\quad$ Knee extensors & $2(0-3)$ & $1(0-3)$ & $1(0-3)$ \\
$\quad$ Ankle plantar flexors & $1(0-3)$ & $1(0-3)$ & $2(0-3)$ \\
Motricity Index & & & \\
$\quad$ Total & $34(1-48)$ & $38(1-54)$ & $38(1-54)$ \\
Hip & $9(0-19)$ & $14(0-19)$ & $14(0-25)$ \\
Knee & $14(0-25)$ & $14(0-25)$ & $14(0-25)$ \\
Ankle & $9(0-19)$ & $9(0-25)$ & $9(0-25)$ \\
\hline
\end{tabular}

Data are presented as median (range).

ICF: International Classification of Functioning, Disability and Health; $t_{0}$ : beginning of training period; $\mathrm{t}_{1}$ : after 6 sessions; $\mathrm{t}_{2}$ : after 12 sessions.

In Table III, the median values of TCT and FAC and the mean values of $10 \mathrm{mWT}$ and $6 \mathrm{minWT}$ are reported. TCT showed significant change at $\mathrm{t}_{1}-\mathrm{t}_{2}(\mathrm{P}=0.0078)$ and $\mathrm{t}_{0}-\mathrm{t}_{2}(\mathrm{P}=0.0039)$. There also was significant change in FAC at $\mathrm{t}_{0}-\mathrm{t}_{1}(\mathrm{P}=0.001)$ and $\mathrm{t}_{0}-\mathrm{t}_{2}(\mathrm{P}=0.001)$. At the beginning of the training period, 5 of the sub-acute patients were able to walk and they performed the $10 \mathrm{mWT}$ and 6 minWT. At $t_{1} 2$ additional patients regained ambulation, and at $t_{2}$ a total of 9 patients were able to walk. For the $10 \mathrm{mWT}$, there was no significant difference in time $\left(\mathrm{P}_{\mathrm{t} 0-\mathrm{t} 1}=0.63, \mathrm{P}_{\mathrm{t} 0-\mathrm{t} 2}=0.46\right)$ or in the number of steps $\left(\mathrm{P}_{\mathrm{t} 0-\mathrm{t} 1}=0.81, \mathrm{p}_{\mathrm{t} 0-\mathrm{t} 2}=0.38\right)$. Significant improvement in walking velocity was achieved at $\mathrm{t}_{1}-\mathrm{t}_{2}(\mathrm{P}=0.0234)$ and $\mathrm{t}_{0}-\mathrm{t}_{2}(\mathrm{P}=0.0078)$. The 6minWT showed a statistically significant change at $\mathrm{t}_{0}-\mathrm{t}_{1}(\mathrm{P}=0.0156), \mathrm{t}_{1}-\mathrm{t}_{2}(\mathrm{P}=0.0195)$, and $\mathrm{t}_{0}-\mathrm{t}_{2}(\mathrm{P}=0.0039)$. Last in Table III, WHS improved significantly from $\mathrm{t}_{0}-\mathrm{t}_{2}(\mathrm{P}=0.0156)$.

\section{Chronic patients}

Eleven chronic patients were evaluated at $t_{0}, t_{1}$, and $t_{2}$. In Table IV, the Ashworth and Motricity Index scales for chronic patients are reported. The Ashworth Scale, measured at hip adductor muscles $\left(\mathrm{P}_{\mathrm{t} 0-\mathrm{t} 1}=0.99, \mathrm{P}_{\mathrm{t} 0-\mathrm{t} 2}=0.99\right)$, at knee extensor muscles $\left(\mathrm{P}_{\mathrm{t} 0-\mathrm{t} 1}=0.50, \mathrm{P}_{\mathrm{t} 0-\mathrm{t} 2}=0.25\right)$, and at ankle plantar flexor muscles $\left(\mathrm{P}_{\mathrm{t} 0-\mathrm{t} 1}=0.99, \mathrm{P}_{\mathrm{t} 0-\mathrm{t} 2}=0.25\right)$ did not reveal significant differences at any of the time periods $\left(t_{0}-t_{1}, t_{0}-t_{2}\right)$ The total score of MI showed significant improvement at the following periods: $t_{0}-t_{1}$ $(\mathrm{P}=0.0156)$, and at $\mathrm{t}_{0}-\mathrm{t}_{2}(\mathrm{P}=0.0078)$. The partial scores of the MI revealed significant improvement at hip level
TABLE V.-Clinical scale for activities and participation ICF domains for chronic patients.

\begin{tabular}{lccc}
\hline \multirow{2}{*}{\multicolumn{1}{c}{ ICF domain }} & \multicolumn{3}{c}{ Period } \\
\cline { 2 - 4 } & $\mathrm{t}_{0}$ & $\mathrm{t}_{1}$ & $\mathrm{t}_{2}$ \\
\hline Trunk Control Test & $61(0-74)$ & $61(0-74)$ & $61(0-74)$ \\
Functional Ambulation Scale & $1(0-3)$ & $2(0-4)$ & $2(0-4)$ \\
10mWT, s & $83.8 \pm 78.4$ & $56.0 \pm 38.5$ & $55.0 \pm 34.4$ \\
10mWT, steps & $23.8 \pm 11.3$ & $18.8 \pm 5.6$ & $19.0 \pm 5.7$ \\
10mWT, m/s & $0.20 \pm 0.12$ & $0.24 \pm 0.13$ & $0.25 \pm 0.16$ \\
6minWT, m & $79.5 \pm 46.8$ & $88.0 \pm 43.3$ & $92.0 \pm 59.3$ \\
Walking Handicap Scale & $2(1-3)$ & $2(1-3)$ & $2(1-3)$ \\
\hline
\end{tabular}

Data are presented as median (range) or as mean $\pm \mathrm{SD}$.

ICF: International Classification of Functioning, Disability and Health; 10mWT: 10-Meter Walk Test; 6minWT: 6-Minute Walk Test.

at $\mathrm{t}_{0}-\mathrm{t}_{1}(\mathrm{P}=0.0156)$ and $\mathrm{t}_{0}-\mathrm{t}_{2}(\mathrm{P}=0.0156)$; at knee level $\left(\mathrm{P}_{\mathrm{t} 0-\mathrm{t} 1}=0.50, \mathrm{P}_{\mathrm{t} 0-\mathrm{t} 2}=0.99\right)$ and at ankle level $\left(\mathrm{P}_{\mathrm{t} 0-\mathrm{t} 1}=0.25\right.$, $\left.\mathrm{P}_{\mathrm{t} 0-\mathrm{t} 2}=0.25\right)$, there were no significant differences.

Table V lists TCT, FAC, 10mWT, 6 minWT, and WHS values. TCT did not differ significantly between assessment periods. However, there was significant change in $\mathrm{FAC}$ at $\mathrm{t}_{0}-\mathrm{t}_{2}(\mathrm{P}=0.0313)$. At the beginning of the training period, 4 of the 11 chronic patients were able to walk and to perform $10 \mathrm{mWT}$ and $6 \mathrm{minWT}$. At $\mathrm{t}_{1}, 2$ patients regained this activity, and at $t_{2}, 7$ patients were able to walk. In the $10 \mathrm{mWT}$, there was no significant change in time $\left(\mathrm{P}_{\mathrm{t} 0-\mathrm{t} 1}=0.99, \mathrm{P}_{\mathrm{t} 0-\mathrm{t} 2}=0.94\right)$ or in the number of steps $\left(\mathrm{P}_{\mathrm{t} 0 \mathrm{t} \mathrm{t}}=0.99, \mathrm{P}_{\mathrm{t} 0 \mathrm{-t} 2}=0.61\right)$; the walking velocity improved significantly at $\mathrm{t}_{1}-\mathrm{t}_{2}(\mathrm{P}=0.0156)$ and at $\mathrm{t}_{0}-\mathrm{t}_{2}(\mathrm{P}=0.0156)$. The 6minWT evidenced a significant improvement at $\mathrm{t}_{1}-\mathrm{t}_{2}(\mathrm{P}=0.0156)$, and $\mathrm{t}_{0}-\mathrm{t}_{2}(\mathrm{P}=0.0313)$. There was no improvement in WHS at any of the assessment periods.

\section{Discussion}

We performed this study to evaluate changes in clinical outcomes induced by overground gait training with Ekso in sub-acute and chronic hemiparetic stroke patients using clinical scales defined by ICF classification, as suggested by Geroin et al. ${ }^{25}$ Recovery of independent ambulation after stroke is a major goal of rehabilitation. However, it is very difficult to choose the best treatment for each individual, and decisions currently are made on a subjective basis. ${ }^{31}$ Literature evidence regarding the use of wearable powered exoskeletons for overground training of stroke patients is very poor. In a recent review ${ }^{8}$ of wearable powered exoskeletons for stroke 


\section{COPYRIGHT $^{(} 2017$ EDIZIONI MINERVA MEDICA}

patients, the authors reported that only four different types of powered exoskeletons had been studied in a small number of stroke patients and the published data were controversial. The authors commented on the need to research the clinical usefulness of other commercial wearable powered exoskeletons to stroke patients. This study is the first to describe the use of Ekso as a gait rehabilitation tool in stroke patients.

\section{Sub-acute patients}

In sub-acute patients, the Ashworth scale did not show a significant difference between the conditions analyzed; no changes in value were observed at hip and knee level whereas an increase in value was observed in plantar flexor muscles $\left(\mathrm{t}_{0}=0, \mathrm{t}_{2}=1\right)$. It is noteworthy that in this small group of patients, high-intensity gait rehabilitation training with the wearable overground device did not increase spasticity.

Total and partial scores of Motricity Index showed a positive increase in value; literature reports ${ }^{33-36}$ of other "stationary devices" confirm these findings. MI evaluated at knee and hip level confirmed that, at the end of the training period $\left(\mathrm{t}_{2}\right)$ with Ekso, patients fully restored a complete active range of motion against gravity. Specifically, the median value of MI at hip level was 14 at the beginning of the training period $\left(\mathrm{t}_{0}\right)$ and reached 19 at $t_{2}$; the median value of MI at knee level was evaluated as 16.6 at $\mathrm{t}_{0}$ and reached 22 at $\mathrm{t}_{2}$. A statistically significant change also was measured at ankle level with a partial but incomplete recovery of active movement (median value $\mathrm{t}_{0}=4.5, \mathrm{t}_{2}=14$ ). This finding may be reflected by the fact that, when the patient wears Ekso, the ankle joint position is fixed.

Statistical differences were found for TCT, FAC, $10 \mathrm{mWT}$ walking velocity and $6 \mathrm{minWT}$ walking endurance. No changes in median TCT values were observed between $t_{0}, t_{1}$, and $t_{2}$, even when observing a modification in the distribution of single values and in the range of measures. An improvement in the median FAC, from non-functional walking $\left(\mathrm{t}_{0}=1.5\right)$ to walking with only supervision and without physical contact $\left(t_{2}=3\right)$, was measured. Mehrholz et al. found that FAC score can predict independent community ambulation 6 months after stroke with high sensitivity and specificity. ${ }^{13}$ These findings confirm the literature data from "stationary devices," 33, 34, 37-41 in which a major positive change in
FAC value was registered in patients treated with body weight treadmill robotic devices compared to traditional overground treatment.

Mean velocity during spontaneous walking in the $10 \mathrm{mWT}$ increased from $0.46 \mathrm{~m} / \mathrm{s}$ before robotic training to $0.56 \mathrm{~m} / \mathrm{s}$ at the end of the training sessions. This prepost difference of $0.10 \mathrm{~m} / \mathrm{s}$ is lower than the Minimally Clinically Important Difference (MCID) for stroke patients of $0.16 \mathrm{~m} / \mathrm{s} .{ }^{25}$ In the sub-acute group, the number of patients able to walk at $\mathrm{t}_{0}$ was 5 , at $\mathrm{t}_{1} 2$ additional patients regained the walking ability and, at $t_{2}, 9$ of the 12 patients achieved ambulation. An analysis of single subjects' values between the three assessments shows that the difference from $t_{0}$ to $t_{2}$ is more than MCID for 6 out of the $12(50 \%)$ patients. Reports from the literature ${ }^{33-44}$ demonstrate improvement in patients' walking velocity after treadmill body-weight support robotic training even if no significant changes occurred from conventional to robotic training.

Similar considerations can be made for the distance covered in $6 \mathrm{minWT}$. The mean distance increases from $157.6 \mathrm{~m}$ at $\mathrm{t}_{0}$ to $205.1 \mathrm{~m}$ at $\mathrm{t}_{2}$. In 6minWT, MCID is set at $50 \mathrm{~m}$, and 8 out of $12(67 \%)$ patients achieved a prepost difference of $>50 \mathrm{~m} .{ }^{25}$

An improvement in WHS was observed at the end of the training period (from 1 at $\mathrm{t}_{0}$ to 2 at $\mathrm{t}_{2}$ ), indicating recovery of household ambulation as described by Perry. ${ }^{31}$ In the small group of sub-acute patients, an increase of the measures of activity in ICF domain was accompanied by an increase in the measure of participation.

Two studies of wearable powered exoskeletons in sub-acute stroke patients reported improved walking independence after wearable robotic walking training for non-ambulatory stroke patients. ${ }^{45,}, 46$ This finding agrees with the results of the present study and are similar to those reported in systematic reviews on the use of treadmill robotic training in non-ambulatory patients early after stroke. ${ }^{13,14}$

Wong et al. described a wearable robotic knee orthosis and reported significant improvement in walking speed for sub-acute stroke patients who had some residual movement and less improvement in patients without voluntary control. ${ }^{47}$ In contrast in our study, we observed improvements for both ambulant and for nonambulant patients. In our study, sub-acute patients performed not only robotic training, but also conventional 


\section{COPYRIGHT $^{(} 2017$ EDIZIONI MINERVA MEDICA}

physiotherapy training. Due to the study design, we were not able to demonstrate if modification in walking abilities resulted from spontaneous recovery, robotic training, conventional treatment, or the integration of all of these factors.

\section{Chronic patients}

In chronic patients, there were no significant changes in Ashworth scale, whereas some differences in MI total score and at hip level were observed. The median MI value at hip level was 9 at $\mathrm{t}_{0}$ and 14 at $\mathrm{t}_{2}$, with partial recovery of active range of motion; no changes in values were observed at knee or ankle levels.

In the activity domain of the ICF, there was no significant change over time in TCT, whereas significant improvement occurred in FAC with an increase from 1 at $\mathrm{t}_{0}$ to 2 at $\mathrm{t}_{2}$. Significant changes in speed and distance were observed. Mean velocity increased from $0.20 \mathrm{~m} / \mathrm{s}$ at $\mathrm{t}_{0}$ to $0.25 \mathrm{~m} / \mathrm{s}$ at $\mathrm{t}_{2}$, and distance covered in $6 \mathrm{~min}$ utes increased from 79.5 to $92 \mathrm{~m}$ over the total evaluation period. The improvements in velocity and distance were less than the MCID for stroke patients $(0.16 \mathrm{~m} / \mathrm{s}$ for velocity, $50 \mathrm{~m}$ for distance). However, the number of patients performing the $6 \mathrm{minWT}$ and $10 \mathrm{mWT}$ was different at each assessment period. Four chronic stroke patients were able to walk at $\mathrm{t}_{0}, 6$ at $\mathrm{t}_{1}$, and 7 at $\mathrm{t}_{2}$. For 3 subjects, the pre-post differences in velocity and distance were greater than those of the MCID.

Among several studies, results of spontaneous walking velocity in chronic patients before and after treadmill body-weight supported robotic treatment disagree. $40,45,48,49$ In our study, chronic patients only underwent robotic overground gait training; for this reason, their improvements in FAC, $10 \mathrm{mWT}$, and $6 \mathrm{minWT}$ are due to the robotic treatment.

Until the present study, literature reports on chronic stroke patients were conducted on ambulant patients. ${ }^{8}$ In our study, we considered ambulant as well as nonambulant chronic stroke patients and we observed improvements in clinical scales for both types of patients.

Louie and Eng also reported that chronic stroke patients do not respond as positively to exoskeletal gait training as do sub-acute patients. ${ }^{8}$ In our study, a statistical improvement in functional ability was observed for sub-acute and for chronic stroke patients.

Overwhelmingly, the literature reports that signifi- cantly positive results, in terms of recovery of functional and independent ambulation, can be reached using repetitive, intensive, and task-oriented exercises based on motor learning. Louie and Eng have questioned the hypothesis that treadmill robotic gait training, characterized by sagittal movement of the legs without movement of the body into the space, can induce a functional result. ${ }^{8}$ Overground exoskeletons require that the patient actively interfaces with the exoskeleton. With powered wearable exoskeleton Ekso, the patient is responsible for maintaining trunk and balance control and for navigating over different surfaces. Contribution of visual spatial and vestibular components, as well as patient engagement, is required.

Consequently, overground gait training with a wearable powered exoskeleton should stimulate motor control and be a good tool for walking rehabilitation in stroke patients. Our findings contrast with literature evidence that reports that a "passive exercise," in which external motors provide the full power of both legs, could potentially reduce the effort of the patient during training at high passive guidance. ${ }^{50}$ However, our results agree with those of Louie and Eng. ${ }^{8}$

\section{Limitations of the study}

This was an open-label study with a small number of recruited stroke patients who had different clinical conditions; there was no control group, and there was no long-term follow-up evaluation. For these reasons, it is not possible to generalize the results of this study even if this work could represent a first attempt to describe the effects provided by a powered wearable robotic device on sub-acute and chronic stroke subjects.

\section{Conclusions}

This study suggests that it is possible to modify clinical outcome measures in sub-acute and chronic post stroke patients after 12 sessions of gait training with a powered wearable robotic exoskeleton after fine-tuning the kinematic gait cycle parameters. It is possible to plan a new individually tailored rehabilitation strategy (including task-oriented gait training) after stroke. Large multicenter randomized controlled trials comparing standard and robotic overground gait training, are warranted to verify the findings of this preliminary study. 


\section{COPYRIGHT $^{(} 2017$ EDIZIONI MINERVA MEDICA}

\section{References}

1. Feigin VL, Krishnamurthi RV, Parmar P, Norrving B, Mensah GA, Bennett DA, et al. Update on the global burden of ischemic and hemorrhagic stroke in 1990-2013: the GBD 2013 study. Neuroepidemiology 2015;45:161-76.

2. Knutsson E, Richards C. Different types of disturbed motor control in gait of hemiparetic patients. Brain 1979;102:405-30.

3. De Quervain IA, Simon SR, Leurgans S, Pease WS, McAllister D. Gait pattern in the early recovery period after stroke. J Bone Joint Surg Am 1996;78:1506-14.

4. Mulroy S, Gronley J, Weiss W, Newsam C, Perry J. Use of cluster analysis for gait pattern classification of patients in the early and late recovery phases following stroke. Gait Posture 2003;18:114-25.

5. Den Otter AR, Geurts AC, Mulder T, Duysens J. Abnormalities in the temporal patterning of lower extremity muscle activity in hemiparetic gait. Gait Posture 2007;25:342-52.

6. Jorgensen HS, Nakayama H, Raaschou HO, Olsen TS. Recovery of walking function in stroke patients: the Copenhagen Stroke Study. Arch Phys Med Rehabil 1995;76:27-32.

7. Kollen BJ, Kwakkel G, Lindeman E. Longitudinal robustness of variables predicting independent gait following severe middle cerebral artery stroke: a prospective cohort study. Clin Rehabil 2006;20:262-8.

8. Louie DR, Eng JJ. Powered robotic exoskeletons in poststroke rehabilitation of gait: a scoping review. J Neuroeng Rehabil 2016;13:53.

9. Edgerton VR, Tillakaratne NJ, Bigbee AJ, de Leon RD, Roy RR Plasticity of the spinal neural circuitry after injury. Ann Rev Neurosci 2004;27:145-67.

10. Maier IC, Schwab ME. Sprouting, regeneration and circuit formation in the injured spinal cord: factors and activity. Philos Trans R Soc Lond B Biol Sci 2006;361:1611-34.

11. Dietz V, Harkema SJ. Locomotor activity in spinal cord-injured persons. J Appl Physiol 2004:96:1954-60.

12. Kwakkel G, Wagenaar RC, Twisk JW, Lankhorst GJ, Koetsier JC. Intensity of leg and arm training after primary middle-cerebral-artery stroke: a randomized trial. Lancet 1999;354:191-6.

13. Mehrholz J, Wagner K, Rutte K, Meissner D, Pohl M. Predictive validity and responsiveness of the functional ambulation category in hemiparetic patients after stroke. Arch Phys Med Rehabil 2007;88:1314-9.

14. Tefertiller C, Pharo B, Evans N, Winchester P. Efficacy of rehabilitation robotics for walking training in neurological disorders: a review. J Rehabil Res Dev 2013;48:387.

15. Turchetti G, Mazzoleni S, Dario P, Saldì D, Guglielmelli E. The impact of robotic technology on neuro-rehabilitation: preliminary results on acceptability and effectiveness. Value Health 2015;18:A363-4.

16. Dobkin BH, Plummer-D'Amato P, Elashoff R, Lee J, SIRROWS Group. International randomized clinical trial, stroke inpatient rehabilitation with reinforcement of walking speed (SIRROWS), improves outcomes. Neurorehabil Neural Repair 2010;24:235-42

17. Chen G, Chan CK, Guo Z, Yu H. A review of lower extremity assistive robotic exoskeletons in rehabilitation therapy. Crit Rev Biomed Eng 2013;41:343-63.

18. Edgerton VR, Leon RD, Harkema SJ, Hodgson JA, London N, Reinkensmeyer DJ, et al. Retraining the injured spinal cord. J Physiol 2001;533:15-22.

19. Zehr EP. Neural control of rhythmic human movement: the common core hypothesis. Exerc Sport Sci Rev 2005;33:54-60.

20. Behrman AL, Lawless-Dixon AR, Davis SB, Bowden MG, Nair P, Phadke C, et al. Locomotor training progression and outcomes after incomplete spinal cord injury. Phys Ther 2005;85:1356-71.

21. Barbeau H. Locomotor training in neurorehabilitation: emerging rehabilitation concepts. Neurorehabil Neural Repair 2003;17:3-11.

22. Beres-Jones JA, Harkema SJ. The human spinal cord interprets velocity-dependent afferent input during stepping. Brain 2004;127:2232-46.

23. Sale P, Franceschini M, Waldner A, Hesse S. Use of the robot assisted gait therapy in rehabilitation of patients with stroke and spinal cord injury. Eur J Phys Rehabil Med 2012;48:111-21.

24. Esquenazi A, Talaty M, Packel A, Saulino M. The ReWalk powered exoskeleton to restore ambulatory function to individuals with thoracic-level motor-complete spinal cord injury. Am J Phys Med Rehabil 2012;91:911-21.

25. Geroin C, Mazzoleni S, Smania N, Gandolfi M, Bonaiuti D, Gasperini G, et al.; Italian Robotic Neurorehabilitation Research Group. Systematic review of outcome measures of walking training using electromechanical and robotic devices in patients with stroke. J Rehabil Med 2013:45:987-96.

26. Bohannon RW, Smith MB. Interrater reliability of a modified Ashworth scale of muscle spasticity. Phys Ther 1987;67:206-7.

27. Fayazi M, Dehkordi SN, Dadgoo M, Salehi M. Test-retest reliability of Motricity Index strength assessments for lower extremity in post stroke hemiparesis. Med J Islam Repub Iran 2012;26:27-30.

28. Franchignoni FP, Tesio L, Ricupero C, Martino MT. Trunk control test as an early predictor of stroke rehabilitation outcome. Stroke 1997;28:1382-5

29. Holden MK, Gill KM, Magliozzi MR, Nathan J, Piehl-Baker L. Clinical gait assessment in the neurologically impaired. Reliability and meaningfulness. Phys Ther 1984;64:35-40

30. Tyson S, Connell L. The psychometric properties and clinical utility of measures of walking and mobility in neurological conditions: a systematic review. Clin Rehabil 2009;23:1018-33.

31. Perry J, Garrett M, Gronley JK, Mulroy SJ. Classification of walking handicap in the stroke population. Stroke 1995;26:982-9.

32. Jones PS, Pomeroy VM, Wang J, Schlaug G, Tulasi Marrapu S, Geva $\mathrm{S}$, et al. Does stroke location predict walk speed response to gait rehabilitation? Hum Brain Mapp 2016;37:689-703.

33. Freivogel S, Mehrholz J, Husak-Sotomayor T, Schmalohr D. Gait training with the newly developed 'LokoHelp' system is feasible for non-ambulatory patients after stroke, spinal cord and brain injury. A feasibility study. Brain Inj 2008;22:625-32.

34. Tong RK, Ng MF, Li LS. Effectiveness of gait training using an electromechanical gait trainer, with and without functional electric stimulation, in sub-acute stroke: a randomized controlled trial. Arch Phys Med Rehabil 2006;87:1298-304.

35. Husemann B, Müller F, Krewer C, Heller S, Koenig E. Effects of locomotion training with assistance of a robot-driven gait orthosis in hemiparetic patients after stroke: a randomized controlled pilot study. Stroke 2007;38:349-54.

36. Tong RK, Ng MF, Li LS, So EF. Gait training of patients after stroke using an electromechanical gait trainer combined with simultaneous functional electrical stimulation. Phys Ther 2006:86:1282-94.

37. Werner C, Von Frankenberg S, Treig T, Konrad M, Hesse S. Treadmill training with partial body weight support and an electromechanical gait trainer for restoration of gait in sub-acute stroke patients: a randomized crossover study. Stroke 2002;33:2895-901.

38. Hesse S, Uhlenbrock D, Werner C, Bardeleben A. A mechanized gait trainer for restoring gait in nonambulatory subjects. Arch Phys Med Rehabil 2000;81:1158-61.

39. Hidler J, Nichols D, Pelliccio M, Brady K, Campbell DD, Kahn JH, et al. Multicenter randomized clinical trial evaluating the effectiveness of the Lokomat in sub-acute stroke. Neurorehabil Neural Repair 2009;23:5-13.

40. Mayr A, Kofler M, Quirbach E, Matzak H, Fröhlich K, Saltuari L. Prospective, blinded, randomized crossover study of gait rehabilitation in stroke patients using the Lokomat gait orthosis. Neurorehabil Neural Repair 2007;21:307-14

41. Schwartz I, Sajin A, Fisher I, Neeb M, Shochina M, Katz-Leurer M, et al. The effectiveness of locomotor therapy using robotic-assisted gait training in sub-acute stroke patients: a randomized controlled trial. PMR 2009; 1:516-23.

42. Pohl M, Werner C, Holzgraefe M, Kroczek G, Mehrholz J, Wingendorf I, et al. Repetitive locomotor training and physiotherapy improve walking and basic activities of daily living after stroke: a single-blind, randomized multicentre trial (DEutsche GAngtrainerStudie, DEGAS). Clin Rehabil 2007:21:17-27.

43. Peurala SH, Tarkka IM, Pitkänen K, Sivenius J. The effectiveness of body weight-supported gait training and floor walking in patients with chronic stroke. Arch Phys Med Rehabil 2005;86:1557-64.

44. Westlake KP, Patten C. Pilot study of Lokomat versus manual-assist- 


\section{COPYRIGHT $^{\circledR} 2017$ EDIZIONI MINERVA MEDICA}

MOLTENI

ROBOTIC EXOSKELETON FOR OVERGROUND GAIT TRAINING

ed treadmill training for locomotor recovery post-stroke. J Neuroeng Rehabil 2009;6:18.

45. Byl NN. Mobility training using a bionic knee orthosis in patients in a poststroke chronic state: a case series. J Med Case Rep 2012;6:216.

46. Ada L, Dean CM, Vargas J, Ennis S. Mechanically assisted walking with body weight support results in more independent walking than assisted over-ground walking in non-ambulatory patients early after stroke: a systematic review. J Physiother 2010;56:153-61.

47. Wong CK, Bishop L, Stein J. A wearable robotic knee orthosis for gait training: a case-series of hemiparetic stroke survivors. Prosthet Orthot Int 2012;36:113-20.
48. Hornby TG, Campbell DD, Kahn JH, Demott T, Moore JL, Roth HR. Enhanced gait-related improvements after therapist- versus roboticassisted locomotor training in subjects with chronic stroke: a randomized controlled study. Stroke 2008;39:1786-92.

49. Pennycott A, Wyss D, Vallery H, Klamroth-Marganska V, Riener R Towards more effective robotic gait training for stroke rehabilitation: a review. J Neuroeng Rehabil 2012;9:65.

50. Israel JF, Campbell DD, Kahn JH, Hornby TG. Metabolic costs and muscle activity patterns during robotic- and therapist-assisted treadmill walking in individuals with incomplete spinal cord injury. Phys Ther 2006;86:1466-78.

Authors' contributions.-Franco Molteni participated in the design and coordination of the study, data collection, and data analyses, and drafted the manuscript. Giulio Gasperini and Marina Gaffuri participated in the design of the study, enrollment and the data analyses and drafted the manuscript. Maria Colombo, Chiara Giovanzana, Chiara Lorenzon, and Nico Farina participated in the design of the study, patients enrollment, and the data analyses. Giovanni Cannaviello participated in the design of the study, data collection, data analyses, and drafted the manuscript. Stefano Scarano participated in the data collection and analyses. Davide Proserpio and Davide Liberali participated in administration of patients' training. Eleonora Guanziroli participated in the design of the study, data collection, data analyses, and drafted the manuscript. All authors read and approved the final manuscript.

Conflicts of interest.-The authors certify that there is no conflict of interest with any financial organization regarding the material discussed in the manuscript. Article first published online: January 24, 2017. - Manuscript accepted: January 23, 2017. - Manuscript revised: January 17, 2017. - Manuscript received: November 30, 2016. 